\title{
Firm age dynamics and causes of corporate bankruptcy: age dependent explanations for business failure
}

\author{
Alexander Kücher ${ }^{1}$ (D) Stefan Mayr ${ }^{1}$. Christine Mitter ${ }^{2} \cdot$ Christine Duller $^{1}$. \\ Birgit Feldbauer-Durstmüller ${ }^{1}$
}

Received: 14 April 2018 / Accepted: 2 September 2018 / Published online: 18 September 2018

(c) The Author(s) 2018

\begin{abstract}
Theories of organizational failure predict that reasons for corporate demise may differ by firm age and life cycle stage. However, large-scale empirical studies that investigate the relationship between firm characteristics and specific causes of failure are scarce. This study therefore aims to shed light on firm mortality and firm age by analyzing a unique data set of bankrupt small and medium-sized enterprises. Separate statistical models for individual causes of failure are developed in which the liabilities of age are abstracted and disentangled from liabilities of size and industry specific variables on firm level. In this regard organizational ecology argumentation is integrated with resource-based view reasoning following the call for multi-theoretic approaches in organizational failure research. Results show that different failure causes dominate at specific stages of organizational life as defined by age quartiles. While young and adolescent firms predominantly fail due to internal shortcomings, mature small and medium-sized enterprises struggle more with increased competition and economic slowdowns.
\end{abstract}

Keywords Business failure · Firm bankruptcy · Insolvency causes · Resource-based view $\cdot$ Small and medium-sized enterprises $\cdot$ Logistic regression analysis

Mathematics Subject Classifcation M20 Business Economics General · L25 Firm Performance: Size, Diversification and Scope · G33 Bankruptcy, Liquidation

Alexander Kücher

alex.kuecher@gmail.com

1 Institute of Management Control and Consulting, Johannes Kepler University, Linz, Austria

2 Salzburg University of Applied Sciences, Puch, Salzburg, Austria 


\section{Introduction}

Small and medium-sized enterprises (SMEs) are crucial for economic stability and growth, making essential contributions to employment and new job creation (Hyder and Lussier 2016). In the European Union, SMEs account for over $99 \%$ of all enterprises, and more than two-thirds of all employed persons work for SMEs (EU 2015). However, bankruptcy and failure continuously affect SMEs worldwide, with especially high firm mortality rates among firms of smaller size (Carter and van Auken 2006; Mayr et al. 2017). Given the economic importance of SMEs, research regarding small-firm bankruptcy is essential for policymakers to foster macroeconomic development, for the many SME stakeholders, such as customers, suppliers, creditors, and employees, who would be affected directly by SME failure, and of course for the managers and owners of their respective firms to become aware of potential threats and challenges to their businesses (Crutzen and Van Caillie 2008). Organizational failure research examines why and how companies fail, but this research has unfortunately been fragmented in recent decades across various disciplines, with no commonly defined framework or research agenda, which reduces the attractiveness and comprehensibility of this research field for non-specialists (AmankwahAmoah 2016; Mellahi and Wilkinson 2010). Moreover, different levels of analysis, various theoretical streams, and diverse definitions of firm failure make comparisons between existing studies difficult (Kücher et al. 2015). However, we can learn from corporate failures; while success can come in many forms, ultimately only a limited set of factors causes bankruptcy.

A voluminous stream of research into organizational failure, embedded in organizational ecology theory, found that smallness, newness, adolescence, and obsolescence are corporate liabilities within firm populations in diverse industries (e.g. Barron et al. 1994; Brüderl and Schüssler 1990; Brüderl et al. 1992; Hannan and Freeman 1984). Thus, higher mortality risks are evident for not only small and young but also adolescent and older firms under certain environmental conditions. Intrinsic to that ecological view is the concept of organizational inertia, meaning that environmental selection processes favor stable firms with high levels of accountability and reliability, and thus determine firm survival probability (Hannan and Freeman 1984). However, organizational ecologists also propose that the benefits of organizational inertia vary across a firm's life cycle, potentially becoming an obstacle to survival when adaptation to new environmental conditions becomes necessary (Hannan 1998). Organizational ecology research has identified that firm age and size influence not only the probability of failing but may also moderate how companies fail, thus making an essential contribution to corporate failure research.

For this study we merge organizational ecology findings with resource-based view theory and argue that the way businesses fail is age dependent and determined by corporate shortcomings in handling various internal and external challenges. These challenges result from missing capabilities, such as lack of experience, poor managerial abilities, or the inability to adapt to environmental needs and vary over firm life cycle stages, thus age may ultimately affect the course and way of failure. By drawing on these theories, we generally claim that business failure is related by differences in available resources, developed and non-developed capabilities, and 
the degree of organizational efficiency, which in turn are essentially moderated by firm age (Esteve-Perez and Manez-Castillejo 2008; Thornhill and Amit 2003). In this regard we predominantly refer to the more voluntaristic, resource-based explanations concerning organizational failure rather than the more deterministic view of environmental selection of the most reliable and accountable organizations from organizational ecology reasoning in argumentation for our hypotheses. However, we consider these two theoretical perspectives as complimentary rather than competing streams and thus follow the call for multi-theoretic approaches in organizational failure research (Mellahi and Wilkinson 2010).

Scholars of organizational failure generally agree that failure results from internal causes, external causes, or a combination of internal and external causes (e.g. Baldwin et al. 1997; Collett et al. 2014; Lukason and Hoffman 2015; Mellahi and Wilkinson 2004). The majority of empirical studies of business failure have matched and compared samples of surviving and non-surviving firms to discover patterns of difference between these two groups (e.g. Brüderl and Schüssler 1990; Esteve-Perez and Manez-Castillejo 2008; Perry 2001; Saridakis et al. 2008). However, many factors that appropriately discriminate between survivors and non-survivors do not necessarily define causes of failure, because business failure and success are not two sides of the same coin (Castrogiovanni 1996). While case studies of individual organizations that fail (e.g. Amankwah-Amoah and Debrah 2010, 2014) or qualitative inquiries among failed entrepreneurs (e.g. Amankwah-Amoah et al. 2018) provide explanations of reasons for failure and the dynamics and interactions between them, few empirical studies to date have examined large samples of failed firms for specific reasons for corporate bankruptcy (e.g. Carter and van Auken 2006; Collett et al. 2014; Hall 1992; Gaskill et al. 1993; Thornhill and Amit 2003), perhaps in part because firm-level data of individual corporations, particularly SMEs, are rare, with access often made more difficult due to confidentiality or discretion. Moreover, even fewer studies have investigated in detail whether and how specific causes of failure are moderated by firm characteristics (e.g. Baldwin et al. 1997; Lukason and Hoffman 2015; Thornhill and Amit 2003). Hence, so far literature has scarcely empirically and comprehensively investigated reasons for failure among SMEs by drawing on large samples and a quantitative research approach.

Aiming at bridging this research gap, the present paper contributes to existing literature in at least three essential ways. First, our analyses benefit from a rich sample of 459 bankrupt firms in a representative, EU-average industrialized Austrian state in 2012. This data set allows investigating the relation between firm age and specific reasons for bankruptcy at firm level in an unprecedented acuteness and up-todateness, separating firm age from firm size and industry effects. Second, we extend existing research by using age quartiles as moderators instead of linear functions of firm age (e.g. Baldwin et al. 1997; Thornhill and Amit 2003) which allows distinctions in terms of growing and falling importance among individual causes of bankruptcy throughout classes of firm ages. Third, findings from qualitative studies of organizational failure models are solidified and extended by an empirical examination of a bigger number of cases. This way, it complements the subjective perceptions of interviewees affected by failure (e.g. Zacharakis et al. 1999; Amankwah-Amoah et al. 2018) with rather objective data recorded in bankruptcy files and documents. 
The remainder of this paper is structured as follows. First, "failure" will be defined for the purpose of this study. Then, the general theoretical background and empirical studies relevant to the development of hypotheses will be presented. The next section describes data collection, along with explaining the relevant dependent and independent variables included in the regression analyses models. Based on the findings and discussions of the models, the final section outlines limitations and possibilities for future research.

\section{Defining failure}

Business economic studies define failure in various ways, from relatively wide understandings, such as deviations from expected and desired results, discontinuance, termination to prevent further losses, and failure to "make a go of it," to definitions in quite narrow terms, such as formal bankruptcy (Cannon and Edmondson 2001; Cochran 1981; Watson and Everett 1996, 1999). Here, we follow the definition used by other empirical studies (e.g. Lussier 1995; Baldwin et al. 1997) in which failed firms are considered to be those involved in court proceedings, such as Chapter 7 or Chapter 11 in the United States. Like Lussier (1995), we do not distinguish here between liquidation and restructuring; "failure" is defined as causing losses to creditors. Moreover, organizational mortality, insolvency, bankruptcy, demise, and failure may all be used synonymously in terms of the above-mentioned definition.

\section{Theory and hypotheses}

\subsection{Resource-based explanations of organizational ecology findings}

Despite strong fragmentation, two main streams can be identified within the field of research into organizational failure. Whereas organizational ecology (Hannan and Freeman 1977, 1984, 1989; Stinchcombe 1965) and industrial organization (Haveman 1992; Tushman and Anderson 1986) are the main theories from the deterministic perspective, several different theories exist in the voluntaristic stream (Amankwah-Amoah 2016; Mellahi and Wilkinson 2004). From the deterministic point of view, the dominant studies traditionally examined which corporate forms perform similar within the same firm populations. In this regard, organizational ecology research discovered that small, young, or adolescent firms have the highest mortality rates, which led to an examination in more detail of the "liabilities of smallness," "liabilities of newness," and "liabilities of adolescence" (Bates and Nucci 1989; Brüderl and Schüssler 1990; Carroll 1983; Dunne et al. 1989; Freeman et al. 1983; Hannan and Freeman 1984; Henderson 1999). While the liability of newness thesis proposes that firm death rates decline monotonically with age, an organization's life cycle may be divided into at least two periods. In the early phase, while firms benefit from initial founding resources, failure risks are moderate (summarized as a "honeymoon" phase). Risks of failure rise to a peak at the 
moment when start-up capital has been depleted, thereafter falling constantly to a lower level. That is, after the honeymoon period, liabilities of adolescence may trigger firm failure (Brüderl and Schüssler 1990). New and adolescent firms may both fail as diverse stakeholders perceive them to be unaccountable and unreliable according to organizational ecology reasoning. Hence, it is presumed that younger firms face disadvantages against already established firms in terms of barriers to market entry, low network connections, problems finding adequate and skilled staff and worse financing conditions. This all originates from reduced legitimacy because young firms may not have yet created reliable routines or do not offer the requested stability many stakeholders seek (Stinchcombe 1965). Indeed, younger firms face substantial internal and external challenges and are therefore characterized by low levels of corporate inertia (Aldrich and Auster 1986). Meanwhile, when adaptation and change is required, high levels of corporate inertia at older companies may also lead to a higher probability of failure (Haveman 1992; Tushman and Anderson 1986). This is summarized as liability of obsolescence, aging, or senescence, and explains that "as organizations age they become less able to respond to new challenges" (Barron et al. 1994: 381) because they improve skills that add increasingly less value to their survival (Hannan 1998).

The second main stream of organizational failure research, summarized as the voluntaristic perspective, explains firm failure by highlighting shortcomings within the firm, especially organizational and psychological shortcomings, that contribute to corporate demise (Mellahi and Wilkinson 2004). By contrast to deterministic reasoning, from this perspective firms' inability to successfully adapt to environmental conditions, existing corporate deficiencies, or faulty actions of management cause failure (Cameron et al. 1987; D’Aveni 1989; Weitzel and Jonsson 1989). Voluntaristic studies, which are primarily based on firm- or individual-level data, have generated several different theoretical streams. One of the most prominent approaches of these refers to the resource-based view (RBV) (Amankwah-Amoah 2016; Lukason and Hoffman 2015). In general, the RBV considers firms' internal characteristics and highlights that developing distinct resources and hard-to-imitate, rare, and valuable capabilities increases the survival probability and enables superior performance by generating a sustainable competitive advantage (Barney 1991). In turn, undeveloped or missing abilities may cause failure (Thornhill and Amit 2003). Voluntaristic theories of failure in general and the RBV in particular primarily focus on internal, firm specific-abilities. Failure is, thus, considered either a result of poor adaptation to environmental needs or of failing to develop essential capabilities for successfully running a business. Thus, corporate shortcomings in handling both internal (more controllable) and external (less controllable) challenges, not environmental conditions, ultimately lead to firm decline and bankruptcy (Collett et al. 2014). Moreover, from this perspective, environmental conditions can be taken as given, explaining why some firms under similar conditions succeed while others fail.

With regard to the benefits of voluntaristic, firm-related argumentation, we refer to RBV explanations to develop our hypotheses concerning relations among firmlevel specifics, concretely firm life cycle stages, and various internal and external reasons for bankruptcy. However, we argue that organizational ecology theory offers complementary, not competing patterns of explanation, contributing to an integrated 
STATISTICAL MODELS

\begin{tabular}{|c|c|c|c|}
\hline & & Theory & Explanations \\
\hline independent variable & FIRM AGE & $\begin{array}{c}\mathrm{OE} \\
\text { (liabilities of age) }\end{array}$ & $\begin{array}{l}\text { OE research identified that firm age plays an } \\
\text { essential role in business failure research. }\end{array}$ \\
\hline expected relation & & OE / RBV & $\begin{array}{l}\text { Firm age may not only define probability for } \\
\text { failure but also the way of firm demise. OE } \\
\text { argumentation is merged with RBV } \\
\text { reasoning. With this regard age may be } \\
\text { considered proxy predictor variable for } \\
\text { differences in efficiency and firm-related } \\
\text { capabilities which influences how firms fail. }\end{array}$ \\
\hline dependent variable & $\begin{array}{l}\text { FAILURE } \\
\text { CAUSE }\end{array}$ & \multicolumn{2}{|r|}{ OE: organizational ecology RBV: resource-based view } \\
\hline
\end{tabular}

Fig. 1 Theoretical framework

perspective of firm failure (Mellahi and Wilkinson 2004; Amankwah-Amoah 2016), to investigate how the causes of corporate insolvency may be affected by firm age. Thus, ecological age dynamics influence not only the probability of failure but also how firms fail (see Fig. 1). In this regard, insolvency due to liabilities of newness and adolescence occurs when firms fail to build a competitive advantage before their initial stocks of capital are exhausted. In terms of the RBV, their failure may thus be attributed to resources and capabilities that are inadequate to successfully market their products and services and therefore cannot generate sufficient cash flows to meet their ongoing liabilities (Thornhill and Amit 2003). By contrast, business failure may also result from external factors if firms lose or lack the ability to adapt to changing environmental conditions. Similarly, the inability to survive under increased competitive pressure drives organizations to failure (Esteve-Perez and Manez-Castillejo 2008). Thus, mismatches between firm-developed abilities, firm resources and environmental requirements lead to insolvency. Failures due to tightened competition or changed market conditions frequently occur when firms suffer "liabilities of obsolescence" (Barron et al. 1994). Although older firms may have developed valuable and rare routines, these capabilities may not guarantee their survival if competitors can imitate them (Thornhill and Amit 2003).

\subsection{Previous empirical studies and development of hypotheses}

Existing studies have identified a variety of causes of failure, both internal and external to the firm (e.g. Baldwin et al. 1997; Boyle and Desai 1991; Gaskill et al. 1993; Theng and Boon 1996). However, no comprehensive or general list of reasons for failure is yet apparent to date. In general, firm bankruptcy results from three different sources: (1) personal factors related to the entrepreneur's or management's personality or characteristics, (2) firm-specific factors and missing resources, and (3) external or environmental conditions (Mayr et al. 2017; Strotmann 2007). Following the categorization of causes of failure in other empirical studies and classification schemes (e.g. Baldwin et al. 1997; Carter and van Auken 2006; Collett et al. 2014; Gaskill et al. 1993), we analyzed the relationships among three external causes and 
seven internal causes in terms of how their probabilities of being responsible for failure are related to company age. We assigned increased competition, economic slowdown, and bad debt to the external, less-controllable sphere, while we see lack of equity, poor business-economic competencies, unqualified management, high cost pressure, challenges in the private domain, poor quality of goods or services, and criminal actions (e.g. fraud) as originating from an internal, more-controllable direction. Key findings of previous studies investigating causes of failure are summarized in Table 1 and serve as a foundation for the development of the following hypotheses.

Referring to the previous argumentation, company age plays a crucial role in determining the causes of failure. Many factors that lead to the failures of younger firms may be less relevant to older companies, because business owners increase their managerial abilities as they actually run their businesses and get to know their real costs and necessary income better year-by-year (Jovanovic 1982). In this regard, Headd (2003) proposed that management is confronted with uncertainty at startup which may result from their inexperience. Hall (1992) highlighted operational problems and undercapitalization as prevalent causes of firm failure, suggesting that different problems may occur during different periods of the business lifecycle. Whereas poor products, inefficient marketing, and inadequate funding cause firm mortality at startup, during the post-launch stage the knowledge and competence of the founder or owner in terms of running the business become essential for survival. Over the long run, strategic foresight gains importance in terms of the firm's ability to adapt to new environmental conditions and needs (Aldrich and Auster 1986; Hall 1992). Other researchers (Baldwin et al. 1997; Ooghe and De Prijcker 2008; Thornhill and Amit 2003) have also found that inappropriate management qualities or skills are predominant causes of young firms' bankruptcies, including managerial or industry-related inexperience, as well as mistakes in strategic decisions, heavy capital expenditures, and shortcomings in planning or insufficient control mechanisms. In an analysis of Canadian bankruptcies, Baldwin et al. (1997) found that basic internal skills and capabilities, such as general and financial knowledge, control instruments, and market development are absolutely essential for firms to survive their early stages. In general, the entrepreneur herself or himself is one of the most critical factors in the failure of young businesses (Jennings and Beaver 1995; Ropega 2011) because young and often small businesses lack the resources to attract skilled staff with special knowledge, wherefore entrepreneurial success may strongly depend on the general and specific capabilities of the owner or founder (Bates 1990; Hall 1992). Given this owner or founder dependence, problems in the private domain, such as an owner's severe illness or divorce, should affect corporate affairs much more strongly in younger firms. Though poor business-economic competencies, such as missing knowledge of finance, calculation, marketing, planning, or distribution, or temporary problems in the private domain may not lead immediately to organizational failure, as firms benefit from their initial founding stock of financial resources, these will however result in failure after this financial stock has been depleted. Thus, a lack of sufficient financial resources at startup makes young firms especially prone to early bankruptcy because they can hardly buffer any internal or external challenges that may arise (Brüderl and Schüssler 1990; Hall 


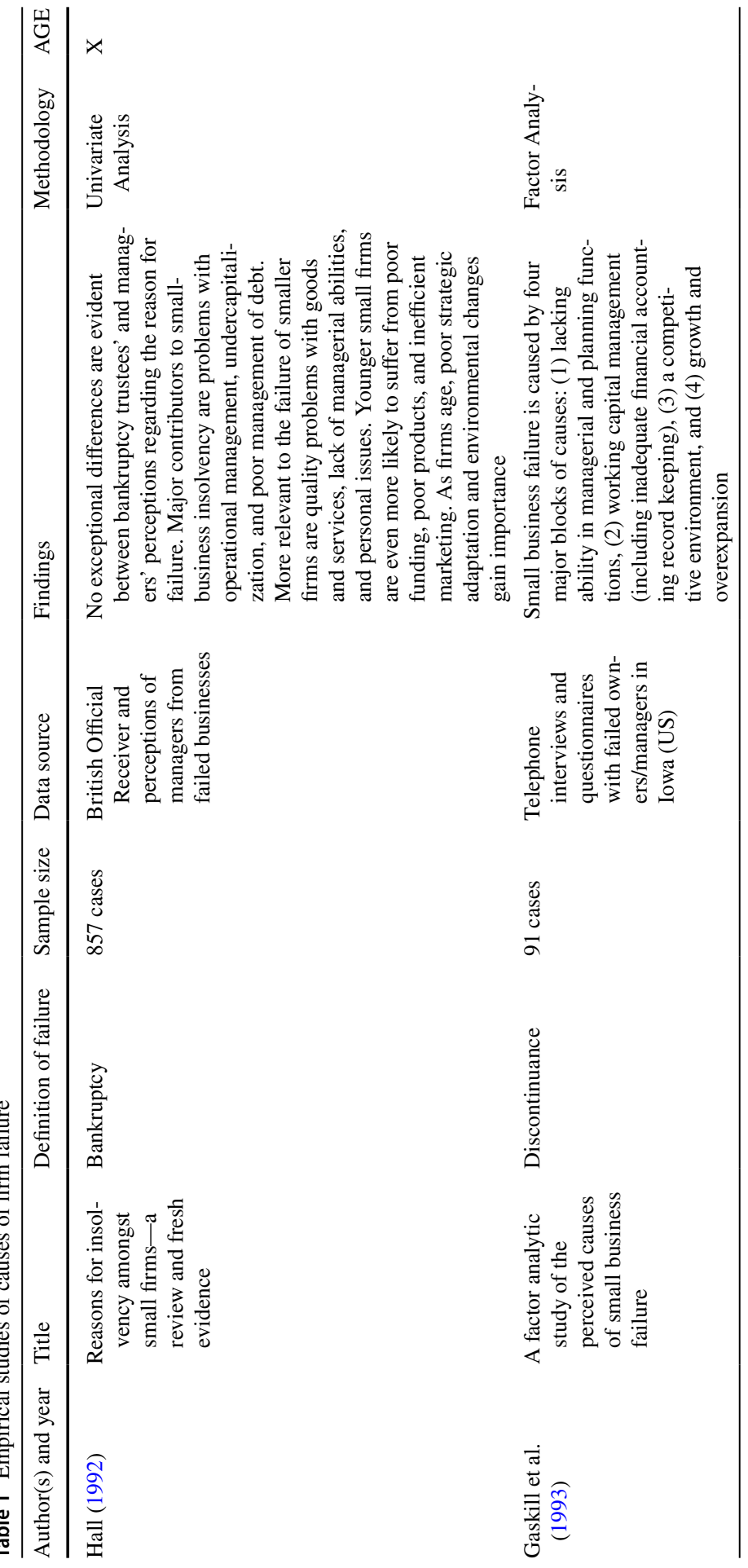




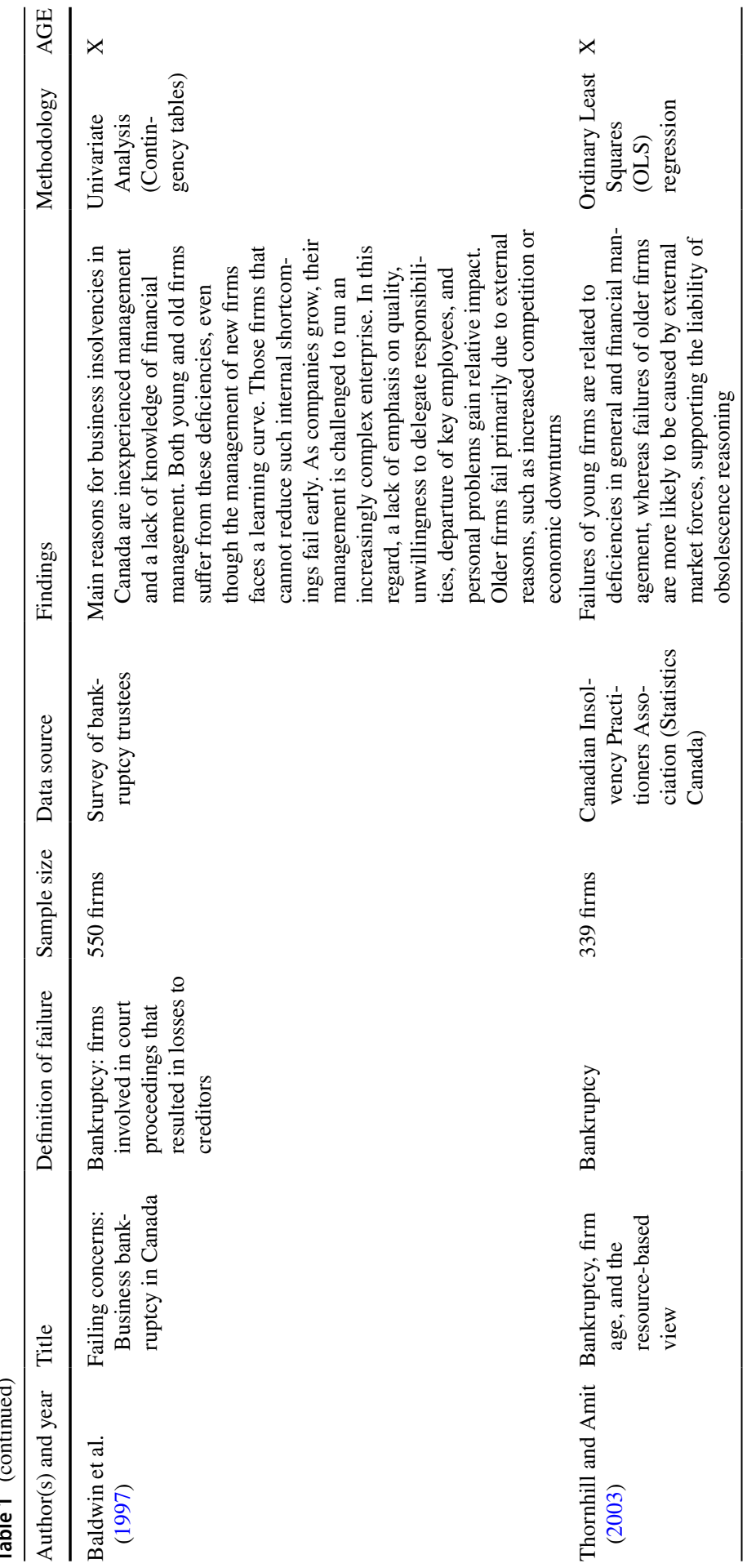




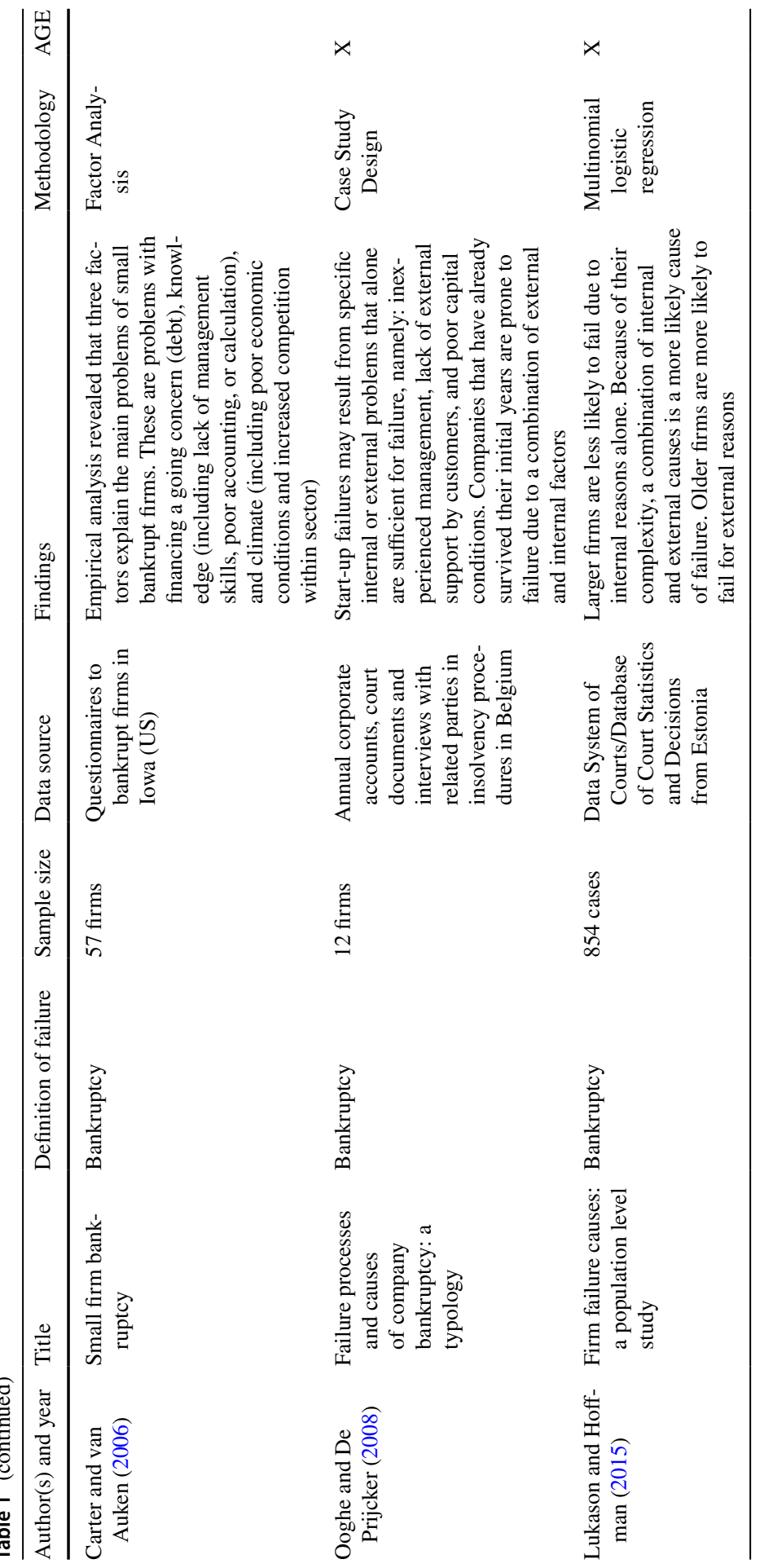


1992). If undercapitalization at startup is avoided and managers of new firms successfully build up essential internal competencies and routines before their capital is depleted, a new set of problems becomes apparent. Managers must increase their strategic foresight and managerial competencies in running a mature, more complex firm. Abilities to delegate responsibilities and retain key personnel gain importance (Baldwin et al. 1997). In this regard, young firms often lack formal structures and clear authorization schemes for employees, which could also open space for criminal action. On the other hand, the relationship between owners or managers and employees in startup firms may be closer and more intimate compared to older businesses, resulting in a working atmosphere of trust and loyalty. Based on these arguments, we derive the subsequent hypotheses.

H1 Older companies are less likely to fail due to a lack of equity.

H2 Older companies are less likely to fail due to poor business-economic competencies.

H3 Older companies are less likely to fail due to unqualified management.

H4 Older companies are less likely to fail due to poor quality of goods or services.

H5 Older companies are less likely to fail as a result of challenges in the private domain.

H6 Failure due to fraud is not affected by company age.

Mature firms face different problems than young companies, especially because older organizations have already developed managerial methods as well as planning and control instruments, and they therefore more likely fail from causes besides operational problems in management or administration. The liability of obsolescence thesis proposes that older firms are vulnerable to changing external conditions, because the resources and valuable capabilities they have developed add less and less value to company performance (Barron et al. 1994; Thornhill and Amit 2003). Moreover, corporate inflexibility hinders necessary adaptation because mature firms are more constrained in their freedom and ability to change or target new business niches, since they have developed durable dependencies with their respective environments. With this regard older firms are also often more bureaucratic than younger start-ups and more likely fail due to high cost pressure resulting from redundant organizational structures in the face of sinking turnover or weakened profit margins in changing industries (Amankwah-Amoah 2016; Levinthal 1991; Ooghe and De Prijcker 2008). Reduced cash flows prevent innovative action, which further deteriorates the position of elder companies in comparison to younger, more flexible businesses with lower overheads. Indeed, the strategy of start-ups in many business sectors will be to benefit from new, innovative products or services and thus to put pressure on well-established firms by generating a competitive advantage (Haveman 1992; Tushman and Anderson 1986). Even though young firms are also confronted with cost pressure as 
they have not reached the break-even in the early phases and thus are not able to cover their costs out of revenues, they frequently rely on sweat equity such as the owners' unpaid labour (Chaganti et al. 1996) as well as the provision of the founders' own equipment such as computers, phones and property without or at lower-than-market charge. Additionally, they often aim at lean structures and a quick and cheap launch of products as well as an agile development of the organization (Blank 2013). This way, they can draw on very flexible cost structures compared to large, established companies whose cost structures are characterized by a high proportion of fixed costs. Looking for instance on the personnel expenses, an essential block of entire costs, these are comparably low in younger firms as costs for loyal employees may significantly rise with seniority of staff and firm age (Navaretti et al. 2014).

A recent analysis of Estonian bankruptcies found that external causes of insolvency beyond management's control are significantly more present with greater firm age (Lukason and Hoffman 2015). Also, Baldwin et al. (1997) showed that external conditions, such as economic downturn or increased competition, predominantly drive older firms into bankruptcy. Notwithstanding the fact that the financial stability of older, more established companies may make them more resistant to worse external conditions due to poor general economic trends or increased competition resulting from sectoral overcapacities, their slack of financial resources can buffer such environmental challenges only for a certain time (Amankwah-Amoah 2016). If an older company's management fails to find or generate new, valuable business activities, its stocks of capital will be depleted and failure cannot be avoided. By contrast, younger, more flexible firms may not yet have established strong ties with their main customers and may therefore more easily seek alternative business opportunities instead of their first, unprofitable initiatives (Aldrich and Auster 1986). Strong ties with long-lasting customers may lead to dependencies and less-intense credit checks of their respective business partners over time. Accordingly, high cost pressures, increased competition within industries, failure due to bad debt, and economic slowdowns are expected to be more frequent reasons leading to the failures of older firms. Therefore, we hypothesize:

H7 Older companies are more likely to fail due to high cost pressures.

H8 Older companies are more likely to fail due to increased competition.

H9 Older companies are more likely to fail due to economic slowdowns.

H10 Older companies are more likely to fail due to bad debt.

\section{Data and method}

\subsection{Sample and metrics}

In previous studies of business failure, empirical data have been gathered from multiple sources, such as court documents or surveys of bankruptcy trustees (Blazy and 
Chopard 2012; Lukason and Hoffman 2015) and perceptions of failing entrepreneurs, managers, or venture capitalists (Hall 1992; Gaskill et al. 1993; Zacharakis et al. 1999). Because managements' or owners' opinions of the reasons why their businesses failed may be biased, we surveyed a more objective source of information, court judgements and documentation of insolvency trustees. ${ }^{1}$ The empirical data involve a sample of bankrupt Austrian SMEs, offering a convenient alternative to existing failure studies grounded mostly in other areas globally, such as North America (e.g. Baldwin et al. 1997; Carter and van Auken 2006; Gaskill et al. 1993; Thornhill and Amit 2003), the United Kingdom (e.g. Hall 1992; Saridakis et al. 2008), and Australia (e.g. Watson and Everett 1996).

The initial sample comprised 459 bankrupt firms, a complete survey of bankrupt organizations and their causes of insolvency in 2012 in Upper Austria, which is, in terms of sectoral composition, comparable on average to other European countries (Creditreform 2012) and extensive in respect of previous empirical studies (see Table 1). We limited the survey to a single state to facilitate data collection and reduce extraneous variables (Carter and van Auken 2006). Moreover, in line with Amankwah-Amoah (2016) the analyzed sample of insolvent firms was not influenced by a major environmental jolt, with 2012 seeing neither a huge crisis (hostile jolt) nor a dramatic enhancement of economic conditions (beneficial jolt). Thus, specific external conditions have not essentially impaired our sample. Data were collected between January 2015 and May 2016 because certain information regarding 2012 insolvency cases could only be obtained after a specific period of time. Court documentation of insolvency cases generally varies by level of detail and descriptive approach, which hinders a structured or common approach to classifying reasons for failure (Lukason and Hoffman 2015). As no general or exhaustive list of bankruptcy causes has yet been developed in the literature, we follow similar classifications of previous studies (e.g. Baldwin et al. 1997; Carter and van Auken 2006; Collett et al. 2014; Gaskill et al. 1993), differentiating respective reasons for bankruptcy according to internal and external spheres as described below (see Table 2). ${ }^{2}$ Because one

\footnotetext{
1 Although these documents are not publicly available in Austria, we obtained access to them for research purposes through a major credit reference agency. International bankruptcy systems can be divided into debtor- and creditor-oriented schemes depending on the rights creditors receive in bankruptcy proceedings (Franks et al. 1996). In Austria legal insolvency procedures may be separated in a principally liquidation-oriented "Konkursverfahren" and a restructuring-oriented "Sanierungsverfahren" and belong to creditor-friendly bankruptcy regimes. Whereas liquidation is carried out by an insolvency trustee, legal restructuring may be done by either the firms' management under surveillance of an insolvency trustee or by an insolvency trustee personally (depending on the obligatory quota debtors are obliged to pay to creditors for debt relief). Independent of type of proceedings insolvency trustees are most commonly experienced lawyers with business economic competencies or experienced management consultants with legal knowledge of insolvency rules. They are listed in an official register and are all experienced and competent enough to classify and name the relevant failure causes for corporate insolvency. Even though no general classification scheme is existing, the breadth of description of failure causes is sufficient for analysis.

${ }^{2}$ In this regard we may highlight that we grouped together most frequently cited blocks of failure sources. "Others", i.e. failures due to unexpected external events such as termination of contract with main customers or natural disasters were underrepresented and thus not individually examined in this study.
} 
Table 2 List of causes of insolvency (dependent variables)

Description

Internal causes

Lack of equity

(1) Too little equity to finance a going concern; (2) no alternative finance source due to insufficient equity basis; (3) liquidity problems due to lack of finance

Poor business-economic competencies (1) Poor or missing accounting, (2) poor or missing calculation, (3) poor or missing financial planning, (4) poor or missing management accounting, or (5) poor or missing marketing knowledge; (6) too little focus on dunning or management of accounts receivables; $(7)$ other operative problems in management and administration

Unqualified management

(1) Missing or poor industry experience; (2) missing or poor industry knowledge; (3) missing or poor management experience

High cost pressure

(1) High number of personnel; (2) too high overheads; (3) floating or little workload that causes problems with meeting fixed costs; (4) high variable costs due to expensive material or subcontractors

Poor quality of goods or services

(1) Operative problems in production of goods or service provision; (2) high expenses due to warranties; (3) failing to provide consistent quality of goods or services; (4) guarantee claims

Private domain

(1) Illness or death of manager or key employees; (2) conflicts between managers or owners; (3) family problems (e.g. divorce); (4) high personal drawings

Fraud

(1) Criminal actions by managers or employees; (2) personal enrichment of individuals; (3) tax fraud and high penalties; (4) high costs for attorneys resulting from respective lawsuits

External causes

Competition

(1) Increased industry competition due to entries of new competitors; (2) price fights to gain additional market share; (3) other changes in competitive environment within sectors

Economic slowdown

(1) General worsening of economic conditions; (2) easing spending power; (3) missing investment incentives

Bad debt

(1) Insolvency due to bad debt of major customer; (2) follow-up insolvency

Others

(1) Termination of contract with main customer; (2) dependency on holding company; (3) escalation of commitment (investment) in certain projects; (4) strategic mistakes by management; (5) failure in patent application and exploitation; (6) natural disasters

dominant cause only rarely leads to failure, we permitted multiple causes of failure for each case, making it possible to examine how company characteristics influence separate factors of failure, thereby generating propositions about the shortcomings to which various age classes of enterprises are more or less prone. Data validity regarding the actual reasons for insolvency was guaranteed through a review of court documents and classification of causes by at least two researchers, thus insolvency causes for each case were assessed in four-eyes principle. The entire survey was done by four researchers, all of them familiar with the underlying codification 
scheme. Whenever, the classification of a certain cause was unclear, it was discussed among all four researchers until a final assignment was agreed upon. Moreover, an expert at the credit reference agency which granted us access to the relevant documents assisted us in reviewing information and additionally provided further caserelated information if he was familiar with the specific insolvency proceedings.

In addition to causes of failure, we obtained information about the year of founding (age), number of employees (size), and business sector (industry) from courtrelated documents, official records, or the internet. Since we analyzed insolvency cases in 2012, the firm-age variable results from the difference between the year of founding and 2012. Insolvency trustees must report the number of employees at the start of insolvency proceedings, so we decided to measure size by the number of employees. Moreover, in contrast to financial figures, this facilitates international comparison because different accounting regulations have no impact (Lukason and Hoffman 2015) and reduces the influence of depleted assets due to crisis (Thornhill and Amit 2003). Industry or business sector were also identified mainly based on court documents or findings on the internet.

Despite great effort, we could not identify the founding years of four bankrupt firms with no employees. Our final sample for regression analysis was thus reduced to 455 cases. We then tested the independent variable company age to predict the probability of specific causes of insolvency (dependent variables) as contributors to firm bankruptcy in individual statistical models. Concretely, we use quartiles to examine the relationships among age and failure causes, enabling a survey of non-monotonic differences and essentially helping to increase the transparency of relationships. To the best of our knowledge, only few existing empirical studies of failure have yet used different age classes for analysis, those that have are mainly descriptive or not theory driven (e.g. Hall 1992; Baldwin et al. 1997). Firm size classified in sole proprietors, micro-firms (one to nine employees), and small and medium-sized enterprises (more than nine employees) according to the definitions suggested by the European Commission (EU 2003), and industry are added as control variables into our separate regression models.

\subsection{Descriptive statistics}

The average age of firms in our sample is 12 years. The oldest firm was 403 years old, and the youngest start-ups did not even survive their first year of existence. As shown in Fig. 2, our overall sample confirms the liability of adolescence thesis, meaning that the number of failing firms rises at first, reaches a peak, and then declines constantly. The liability of smallness is also confirmed, with the highest number of bankruptcies found for firms with fewer than 10 employees. The largest firm in our sample employed 143 persons, while the smallest enterprises were all sole proprietors with zero employees. About $46 \%(n=212)$ of failed businesses were operating as service providers (including the hotel and restaurant industries). Construction and building companies $(n=120)$, trade firms $(n=68)$, and the manufacturing industry $(n=24)$ were the other main sector categories used as control variables (see Table 3 ). 


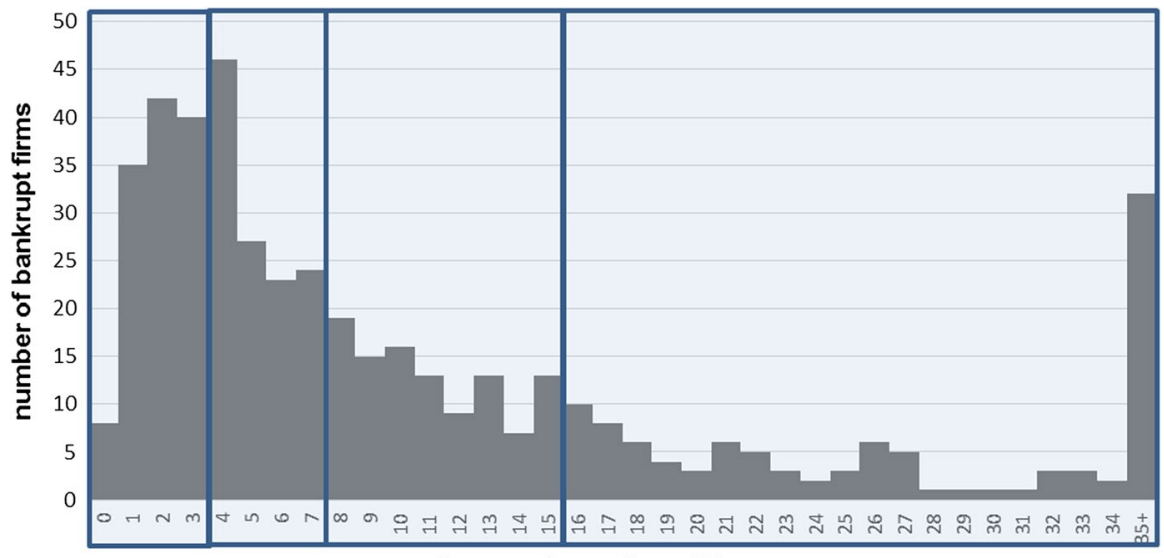

firm age / quartiles of firm age

Fig. 2 Number of failing firms by age and age quartiles

Concerning the causes of insolvency, a lack of business-economic competencies was the most frequently identified cause of firm bankruptcy $(n=207 ; 45 \%)$. Lack of equity to finance a going concern $(n=163 ; 36 \%)$ and high cost pressures $(n=136$; $30 \%$ ) were the other most relevant internal shortcomings of the bankrupt firms in our sample. The most impactful external cause of failure (30\%) was increased competition in firms' respective industries. Still, in $28 \%$ of bankrupt firms, incompetent or unqualified management was responsible for failure, meaning the owners or managers were attested to have no or too little management or industry-related experience. In general, the most important reasons affecting the failure of small businesses identified in the literature are relatively similar in our sample (e.g. Baldwin et al. 1997; Carter and van Auken 2006; Gaskill et al. 1993; Hall 1992). Internal reasons dominate firm failure, while increased competition is still a dominant cause of bankruptcy in light of stagnating markets and lowered barriers to entry in many sectors. Table 4 provides first insights in the association between causes and age, showing the bivariate frequencies as well as the conditional proportions for the different age groups as well as the different causes. Due to missing information on firm age of four cases frequency statistics of failure causes by age group base on $n=455$ in Table 4.

\subsection{Statistical methodology}

To test our hypotheses we performed several binary logistic regression analyses, one for each cause of failure as dependent variable, all of them with control variables industry and firm size as well as predictor variable firm age (Table 5). Starting point of a logistic regression analysis is the probability of an event y (cause of failure), which is referred to as $\pi=\operatorname{Pr}(\mathrm{y}=1)$.

Hence, our model can be specified as follows, whereby $\mathrm{F}$ can stand for any arbitrary distribution function $\pi=\operatorname{Pr}(\mathrm{y}=1)=\mathrm{F}\left(\beta_{0}+\beta_{1} \mathrm{x}_{1}+\cdots+\beta_{\mathrm{k}} \mathrm{x}_{\mathrm{k}}\right)=\mathrm{F}(\mathrm{z})$. Choosing the 
Table 3 Descriptive statistics

\begin{tabular}{|c|c|c|}
\hline $\mathrm{n}=459$ & No. in sample & $\%$ of sample \\
\hline \multicolumn{3}{|l|}{ Independent variables } \\
\hline \multicolumn{3}{|l|}{ Predictor variable } \\
\hline \multicolumn{3}{|l|}{ Age (quartiles) } \\
\hline $0-3$ years & 125 & 27 \\
\hline $4-7$ years & 120 & 26 \\
\hline $8-15$ years & 105 & 23 \\
\hline More than 15 years & 105 & 23 \\
\hline Missing & 4 & 1 \\
\hline \multicolumn{3}{|l|}{ Control variables } \\
\hline \multicolumn{3}{|l|}{ Size (SME definition) } \\
\hline 0 employees & 149 & 32 \\
\hline 1-9 employees & 193 & 42 \\
\hline More than 9 employees & 117 & 26 \\
\hline \multicolumn{3}{|l|}{ Industry } \\
\hline Service & 212 & 46 \\
\hline Construction/building & 120 & 26 \\
\hline Trade & 68 & 15 \\
\hline Manufacturing industry & 24 & 5 \\
\hline Miscellaneous & 35 & 8 \\
\hline \multicolumn{3}{|l|}{ Dependent variables } \\
\hline \multicolumn{3}{|l|}{ Internal causes } \\
\hline Lack of equity & 163 & 36 \\
\hline Poor business economic competencies & 207 & 45 \\
\hline Unqualified management & 128 & 28 \\
\hline High cost pressure & 136 & 30 \\
\hline Poor quality of goods or services & 36 & 8 \\
\hline Private domain & 82 & 18 \\
\hline Fraud & 31 & 7 \\
\hline \multicolumn{3}{|l|}{ External causes } \\
\hline Competition & 137 & 30 \\
\hline Economic slowdown & 78 & 17 \\
\hline Bad debt & 49 & 11 \\
\hline
\end{tabular}

common logistic distribution function for $\mathrm{F}$, the logit model with the linear predictor $\mathrm{z}$ results in

$$
\pi=\operatorname{Pr}(\mathrm{y}=1)=\frac{\exp (\mathrm{z})}{1-\exp (\mathrm{z})} \quad \text { with } \mathrm{z}=\beta_{0}+\beta_{1} \mathrm{x}_{1}+\cdots+\beta_{\mathrm{k}} \mathrm{x}_{\mathrm{k}}
$$

Solving these equations using the inverse logistic distribution function, we derive 


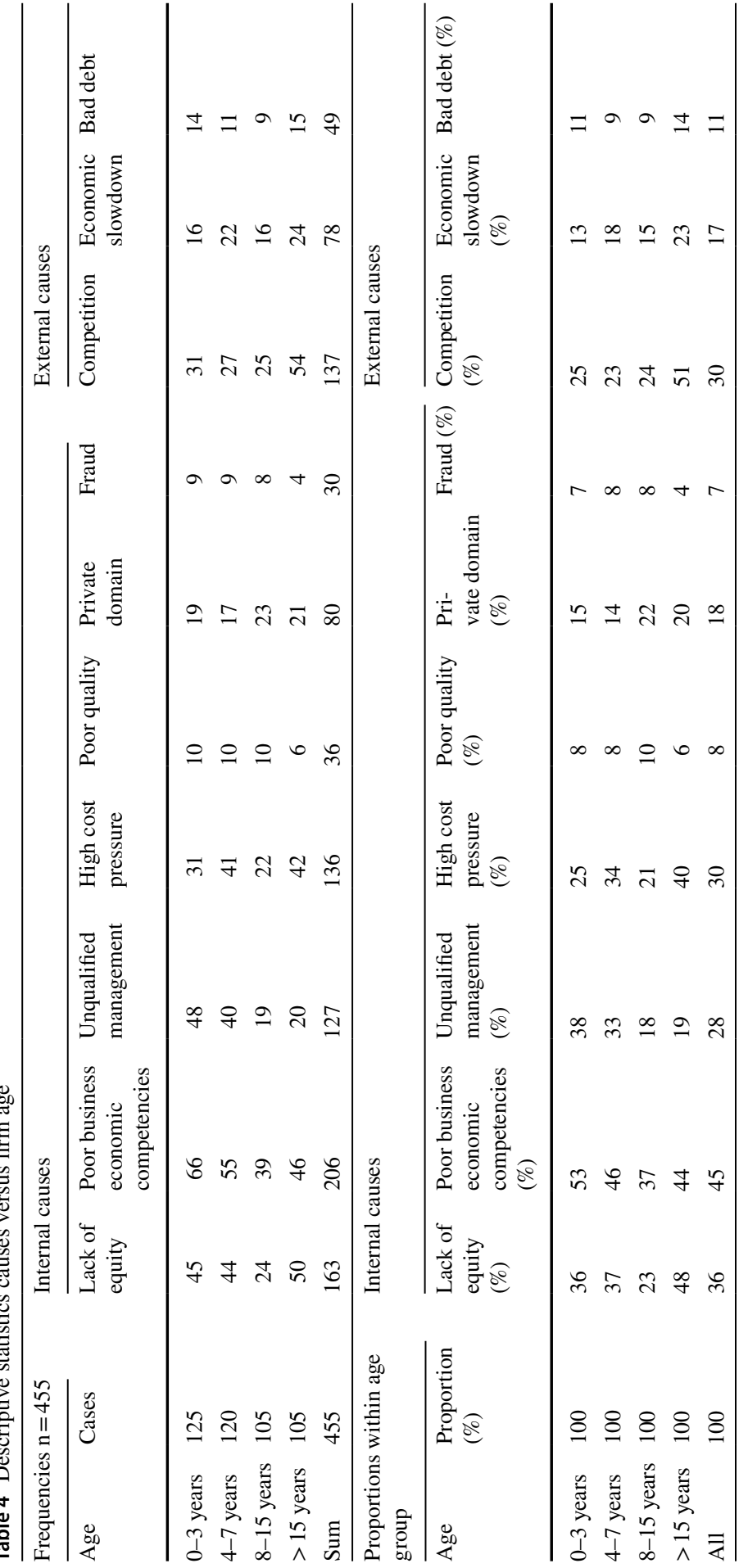

\section{블 Springer}




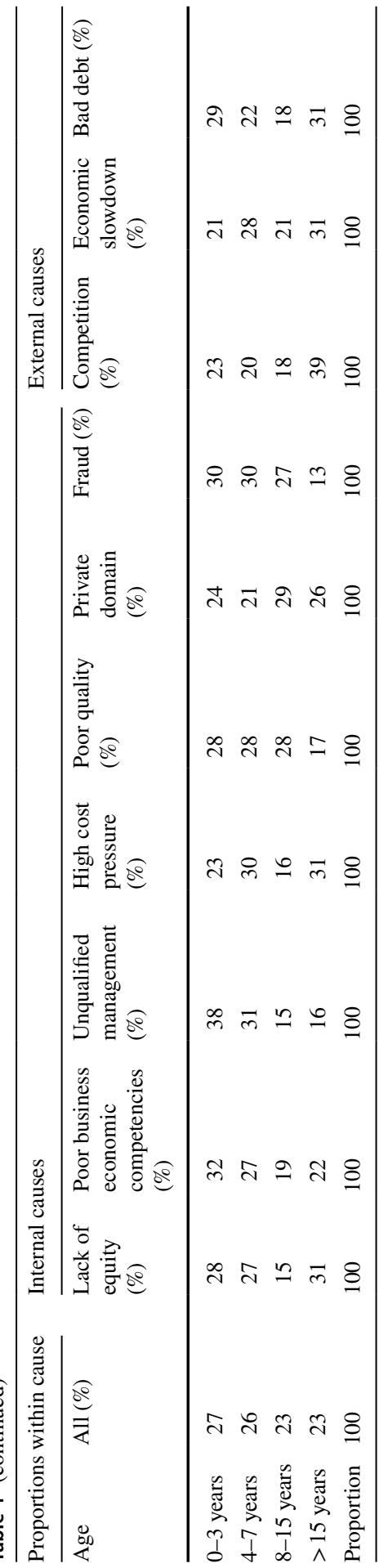




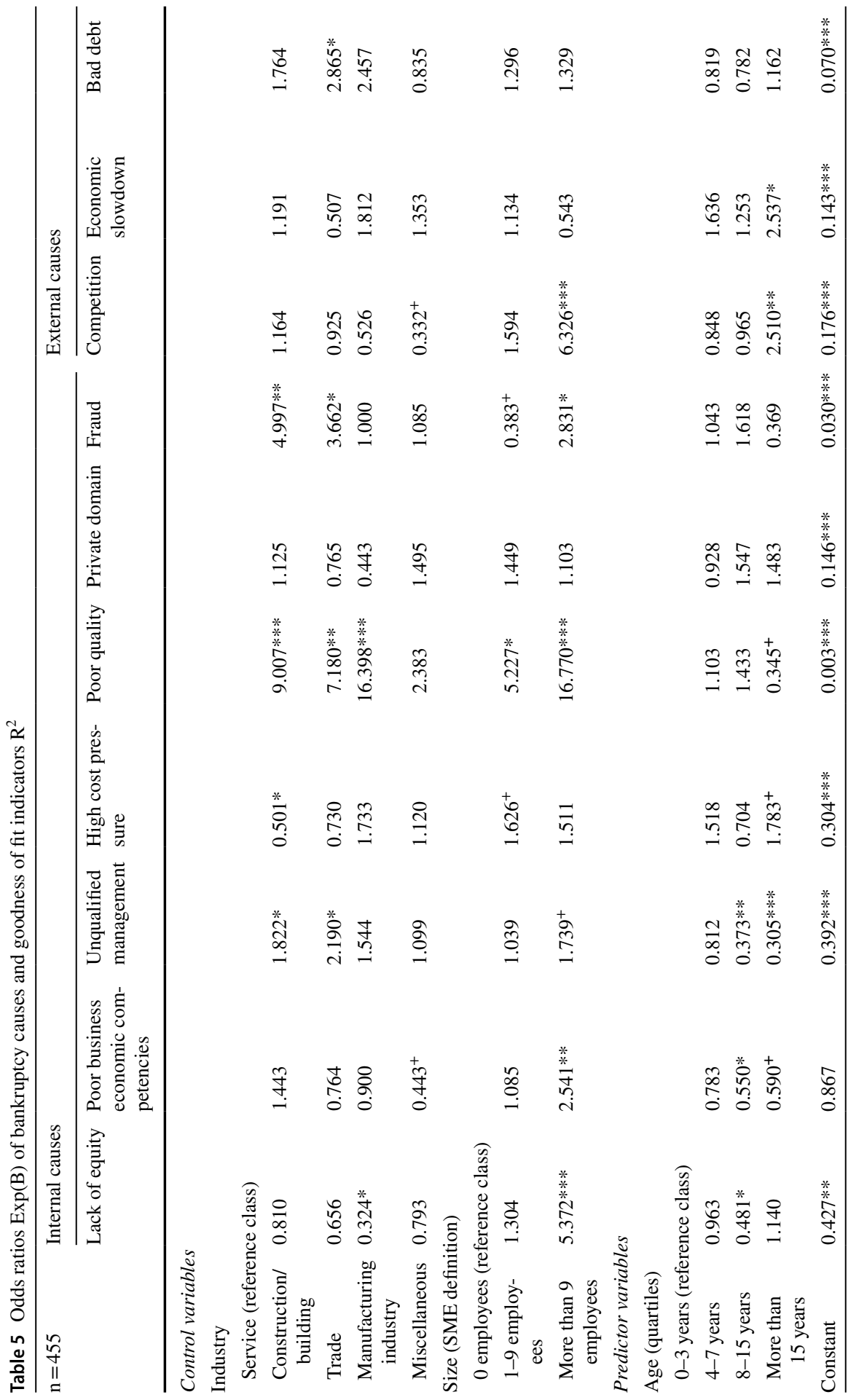




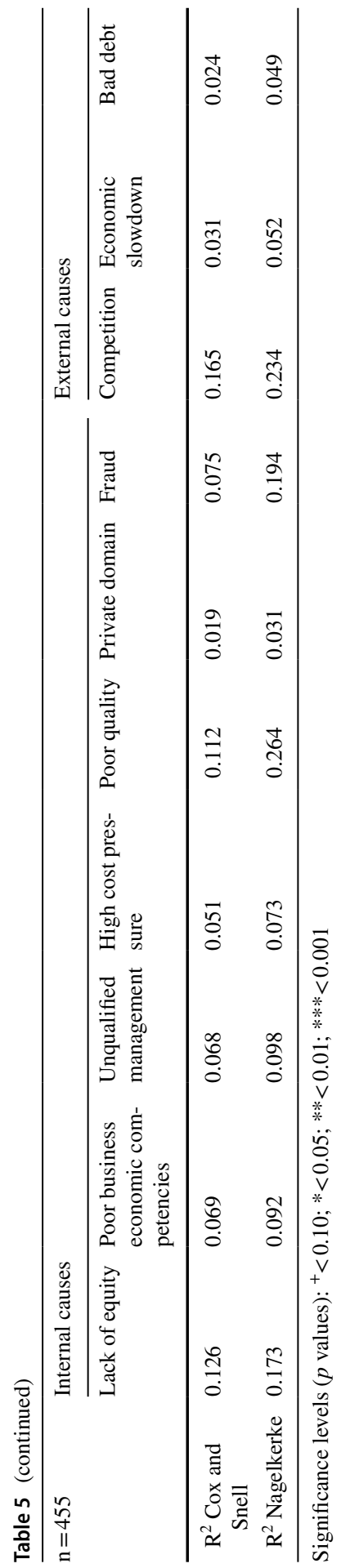




$$
\log \left(\frac{\pi}{1-\pi}\right)=\log \left(\frac{\operatorname{Pr}(\mathrm{y}=1)}{1-\operatorname{Pr}(\mathrm{y}=1)}\right)=\log \left(\frac{\operatorname{Pr}(\mathrm{y}=1)}{\operatorname{Pr}(\mathrm{y}=0)}\right)=\beta_{0}+\beta_{1} \mathrm{x}_{1}+\cdots+\beta_{\mathrm{k}} \mathrm{x}_{\mathrm{k}}
$$

The logistic regression analysis offers the following interpretation: If the value of the variable $x_{i}$ is increased by 1 (and all others are unchanged), then the odd, i.e. the ratio event to non-event $\pi /(1-\pi)$ increases by the factor $\exp \left(\beta_{\mathrm{i}}\right)$ (Hilbe 2009).

In order to test the significance of the explanatory variables, the Wald Test was applied. To select variables, we used stepwise backward selection, whereby a change of log-likelihood served as the criterion. Concerning goodness-of-fit statistics, the Pseudo R-squared measures of Cox and Snell and Nagelkerke were used. The correlations of the independent variables were rather low, so there were no hints indicating any problems with multicollinearity. To have a fast look on the results only the values for the odds ratios $\exp (\beta)$ are reported, as they are easily interpretable. Interpreting the results for Hypothesis 6 is a special case, because for statistical reasons it is not possible to get a significant result for independence, so in this case a non-significant result would confirm the theoretical hypothesis.

\section{Results}

\subsection{Regression results}

Logistic regression results indicate that firms in the first quartile of age and those in the second quartile do not have significantly different reasons for failure. Hence, all firms that fail before their eighth year of existence are prone to nearly the same causes of failure. Whereas the odd (or risk) of failure due to a lack of equity is statistically not different between failed firms in age quartile 1 and age quartile 2, failure due to a lack of equity is about half as high $(p<0.05)$ for those companies that fail at an age between eight and 15 years (quartile 3) compared to those that fail in earlier years. However, the overall relationship seems to be non-monotonic, meaning that the risk of failure due to a poor financial situation again increases for older firms. Poor business-economic competencies and unqualified management are significantly reduced causes of firm failure for older companies. The risk of failure due to a lack of financial, marketing, or controlling knowledge is $41 \%$ less likely $(p<0.10)$ for firms that are older than 15 years compared to their younger competitors. Moreover, these firms are about $70 \%$ less likely $(p<0.001)$ to fail due to unqualified management and $65 \%$ less likely $(p<0.10)$ to fail as a result of problems with the quality of their products or services. Firm age does not significantly influence bankruptcy resulting from challenges in the private domain.

Hypotheses 8 and 9 propose that the impact of external causes should be greater in the bankruptcies of older firms, and our regression results confirm these assumptions. Companies that fail at or after an age of 15 years have about a 2.5 times higher risk of failure due to increased competition $(p<0.01)$ or economic slowdown $(p<0.05)$. Moreover, many mature firms may have developed bureaucratic structures and are confronted with high personnel costs or dependencies on suppliers and 
Table 6 Summary of hypotheses and expected relations of firm age

\begin{tabular}{llll}
\hline & Hypothesis & Expected relation & Results \\
\hline Internal causes & & & \\
Lack of equity & $\mathrm{H} 1$ & $(-)$ & Non monotonic \\
Poor business economic competencies & $\mathrm{H} 2$ & $(-)$ & Confirmed \\
Unqualified management & $\mathrm{H} 3$ & $(-)$ & Confirmed \\
High cost pressure & $\mathrm{H} 7$ & $(+)$ & Confirmed \\
Poor quality of goods or services & $\mathrm{H} 4$ & $(-)$ & Confirmed \\
Private domain & $\mathrm{H} 5$ & $(-)$ & Not confirmed \\
Fraud & $\mathrm{H} 6$ & $(0)$ & Confirmed \\
External causes & & $(+)$ & Confirmed \\
Competition & $\mathrm{H} 8$ & $(+)$ & Confirmed \\
Economic slowdown & $\mathrm{H} 9$ & $(+)$ & Not confirmed \\
Bad debt & $\mathrm{H} 10$ &
\end{tabular}

materials that they may be unable to meet in the face of weakened margins in harder economic times. As a result, failures due to high cost pressures are significantly more likely $(p<0.10)$ in the bankruptcies of older firms. By contrast, bankruptcy grounded in bad debt or criminal action (fraud) is unrelated to firm age, according to our data. Regarding firm age as a predictor of the respective causes of insolvency, most regression results are as expected, confirming our hypotheses (see Table 6). Whereas younger organizations prevalently fail due to firm-internal problems, such as poor business-economic competencies, unqualified management, and poor quality of goods or services, external forces such as increased competition or economic slowdown gain relative importance for the failure of mature companies. Hence, according to our results (see Table 5), company age seems to be a good predictor of organizational problems, agreeing with previous studies of age-related failure causes (e.g. Baldwin et al. 1997; Lukason and Hoffman 2015; Thornhill and Amit 2003).

\subsection{Discussion of results}

Young and adolescent firms, we propose, are in the process of establishing routines to constantly reproduce and distribute quality goods and services at constant costs. Those managing to survive the initial and subsequent periods, to escape the liabilities of newness and adolescence may be prone to failure for other reasons than younger organizations (Thornhill and Amit 2003). Our results broadly confirm these arguments. Without a doubt, major challenges from both inside and outside confront young firms. However, according to the findings presented here, young firms are essentially more likely to fail due to their own internal shortcomings resulting from deficiencies in management and essential economic competencies, often including little knowledge of their respective industries, correct calculation and financial accounting, and underestimation of the equity needed for business activities. Moreover, customers expect quality products and services consistently, which younger 
firms often cannot deliver. As companies age, these problems lose relevance; surviving firms have gained relevant knowledge and have ideally allocated their scarce resources to valuable capabilities that generate a competitive advantage or at least allow them to stay in the market. Our findings highlight that this process can take up to 8 years as there were no significant differences in causes for failure identified between firm bankruptcies in age quartile 1 and age quartile 2 .

Young and often small companies aim either to operate in niches or to be innovative and follow new business paths to compete with older and many times larger competitors (Dean et al. 1998; Tushman and Anderson 1986). As a result, older, established firms are prone to bankruptcy if they persist in exploiting the same resources under changed circumstances and thus become stuck in routines that deliver less and less profit. Strategic foresight, adaptability, and innovativeness are key capabilities in changing external environments for older firms to avoid failure due to external conditions. Older firms must secure their previously developed market share against the imitation of their capabilities. Reducing bureaucratic procedures and costly organizational structures are essential for established firms in saturated markets. Summing up, the findings of this study show that older companies (age quartile 4) are significantly more prone to failures due to high cost pressures, increased competition, and economic slowdowns than are younger firms.

\section{Conclusion}

Despite notable, though fragmented, scholarly interest in studies of business failure in recent decades, there is still need to increase our understanding of why firms fail, an essential step towards avoiding failure. Generally, access to firm-level data regarding bankrupt companies is scarce for reasons of confidentiality and discretion. Moreover, comprehensiveness, and even more important, objectivity of respective data can only be obtained from sources involved but not affected by firm failure (Zacharakis et al. 1999). This study has the strength of a rich and objective data set and takes a unique approach in investigating the influence of firm age quartiles on specific reasons for corporate bankruptcy at firm level. This approach compared to existing studies allows age dynamics to be examined in a different way than linear functions. Furthermore, age effects are abstracted from liabilities of size in individual statistical models of specific failure causes which is an essential contribution to existing business failure research and which may also extend organizational ecology findings. Here, the liabilities of age were translated into resource-based terms. After analyzing our sample of 455 bankrupt businesses, we conclude that firms are indeed confronted by different organizational challenges over their lives which determine the way of failure of these organizations. These results are a relevant addition to existing knowledge.

By integrating organizational ecology and RBV, this paper follows the call for analyzing business failure from a multi-theoretic perspective (Mellahi and Wilkinson 2010). In this regard the liability of age theses constituted the basis for developing hypotheses from a RBV perspective concerning the relation between organizational efficiency, developed capabilities and firm resources and 
specific reasons for failing of SMEs. The findings from this firm-level study may by implication enrich organizational ecology research at population level. Thus, organizational ecology scholars may benefit from the findings regarding causes of failure that go beyond the general firm exit rates and liability of age theses identified at population level. This is in line with previous research that claims for an age dependent analysis of firm performance (Henderson 1999). For instance, our findings suggest that causes of firm failures in quartile 1 and quartile 2 do not significantly differ, and an overall non-monotonic relationship exists between failing due to a lack of equity and firm age. These results may especially extend respective research concerning liabilities of newness and adolescence. Even though previous population ecology studies have identified that the "honeymoon" phase in which new firms benefit from financial resources at founding may be varying (Brüderl and Schüssler 1990; Fichman and Levinthal 1991), defining failed firms from age quartile 1 as failures due to liabilities of newness and those from age quartile 2 as failures due to liabilities of adolescence in this study, seems appropriate to give a first impression of potential differences between these two exit patterns. Moreover, the risk of failing due to a lack of equity reduces not before existing at least 8 years, when firms have presumably escaped the liabilities of adolescence. Our results also confirm that failure causes of younger firms clearly differ from reasons for failures of matured firms. Hence, analyzing populations of organizational forms with specific resources or capabilities would further increase our understanding of age-varying mortality patterns in such populations.

In summary, the findings of our regression analyses confirm that there are significant relationships among firm age and causes of insolvency. These results may be insightful for practitioners, in terms of existing challenges during their entrepreneurial ventures across their life cycles, and for scholars by extending previous studies and potentially grounding avenues for further research. With regard to the first group one may highlight that organizational failure causes diverse financial, social and emotional costs to those who fail (Amankwah-Amoah 2016). Thus, risk awareness in terms of potential threats during life cycle stages may help to avoid common sources for failure and repeat the mistakes others may have already made. While failed entrepreneurs are shown to reflect and learn from their own mistakes when starting a new business (Amankwah et al. 2016), SME managers may also learn from the failures of others (Madsen and Desai 2010). This way, they can increase their self-awareness in terms of potential deficits they or their organizations have. Moreover, findings may also be relevant to governmental institutions to initiate programs to assist SMEs with appropriate training courses for fostering and supporting the economic development of these specific types of organizations by highlighting common failure paths.

With regard to the scientific community, our findings concerning the influence of firm age on business failure reasons, are in line with existing research (e.g. Baldwin et al. 1997; Lukason and Hoffman 2015; Thornhill and Amit 2003); however, we extend existing work by implementing age categories instead of linear relationships to gain unique insights into the causes of failure among different age-based categories of SMEs. The control variable of firm size also shows a significant and distinct influence on causes of failure. By examining the respective influences of 
firm age and controlling for firm size we could disentangle the pronounced effects of the liabilities of age (liabilities of newness, adolescence, and obsolescence) and the liability of size on the individual causes of failure, highlighting the different impacts of each determinant. Discussions regarding the identified relationships for firm size are an under-researched sub-field of business research that should be investigated further (Lussier and Sonfield 2015).

Concerning the above findings, one might argue that causes of firm mortality are affected by size or age not one dimensionally but in combination as companies grow and mature. Here, the benefit of process models can be highlighted. Our results do, however, already agree with essential findings in this regard (e.g. Argenti 1976; Ooghe and De Prijcker 2008). Ooghe and De Prijcker (2008) recently characterized start-up failure caused by lack of managerial or industry-related experience, insufficient control mechanisms, and operational inefficiencies. Many new firms face difficulties in providing high-quality products or services and lack sufficient starting capital to solve initial internal and external challenges. The findings here support this specific type of failure. By contrast, mature, well-established firms may become apathetic, insisting on strategies that had been previously successful but that no longer fit with changed environmental conditions. The developed bureaucracy and inflexibility of older firms make them much more prone to external causes of failure, such as increased competition and economic slowdown. Our results also confirm this type of failure process. Nevertheless, between these two extremes of unsuccessful start-ups and apathetic older companies, other dynamics of failure also exist. Thus, empirical analysis of the causes of insolvency that utilizes life-cyclespecific variables (e.g. combinations of age and size determinants in a longitudinal study) or pre-bankruptcy performance is one potential avenue for further research. We also believe that examination of additional, firm- or entrepreneur-specific or manager-related variables, such as gender, education, or experience, may refine our understanding of relevant causes of failure and how they affect bankruptcy. A bigger sample, no doubt, perhaps with cross-border or multi-year data, would increase the generalizability of the examined relationships. Furthermore, qualitative case studies, not quantitative analysis, may be more appropriate to examine the individual dynamics of roads to bankruptcy.

Acknowledgements Open access funding provided by Johannes Kepler University Linz.

Open Access This article is distributed under the terms of the Creative Commons Attribution 4.0 International License (http://creativecommons.org/licenses/by/4.0/), which permits unrestricted use, distribution, and reproduction in any medium, provided you give appropriate credit to the original author(s) and the source, provide a link to the Creative Commons license, and indicate if changes were made.

\section{References}

Aldrich H, Auster ER (1986) Even dwarfs started small: liabilities of age and size and their strategic implications. Res Org Behav 8:165-198

Amankwah-Amoah J (2016) An integrative process model of organisational failure. J Bus Res 69(9):3388-3397 
Amankwah-Amoah J, Debrah YA (2010) The protracted collapse of Ghana airways: lessons in organizational failure. Group Org Manag 35(5):636-665

Amankwah-Amoah J, Debrah YA (2014) Air Afrique: the demise of a continental icon. Bus Hist 56(4):517-546

Amankwah-Amoah J, Boso N, Antwi-Agyei I (2016) The effects of business failure experience on successive entrepreneurial engagements: an evolutionary phase model. Group Org Manag 43(4):648-682

Amankwah-Amoah J, Antwi-Agyei I, Zhang H (2018) Integrating the dark side of competition into explanations of business failures: evidence from a developing economy. Eur Manag Rev 15:97-109

Argenti J (1976) Corporate collapse: the causes and symptoms. McGraw-Hill Publishing, Berkshire

Baldwin J, Gray T, Johnson J, Proctor J, Rafiquzzman M, Sabourin D (1997) Failing concerns: business bankruptcy in Canada Ottawa. Analytical Studies Branch, Statistics Canada, Ottawa

Barney J (1991) Firm resources and sustained competitive advantage. J Manag 17(1):99-120

Barron DN, West E, Hannan TM (1994) A time to grow and a time to die: growth and mortality of credit unions in New York City, 1914-1990. Am J Sociol 100(2):381-421

Bates T (1990) Entrepreneur human capital inputs and small business longevity. Rev Econ Stat 72:551-559

Bates T, Nucci A (1989) An analysis of small business size and rate of discontinuance. J Small Bus Manag 27(4):1-7

Blank S (2013) Why the lean start-up changes everything. Harvard Bus Rev 91(5):63-72

Blazy R, Chopard B (2012) (Un)secured debt and the likelihood of court-supervised reorganization. Eur J Law Econ 34(1):45-61

Boyle RD, Desai HB (1991) Turnaround strategies for small firms. J Small Bus Manag 29(3):33-42

Brüderl J, Schüssler R (1990) Organizational mortality: the liabilities of newness and adolescence. Adm Sci Q 35(3):530-547

Brüderl J, Preisendorfer P, Ziegler R (1992) Survival chances of newly founded business organization. Am Sociol Rev 57:227-242

Cameron KS, Kim MU, Whetten DA (1987) Organizational effects of decline and turbulence. Adm Sci Q 32:222-240

Cannon MD, Edmondson AC (2001) Confronting failure: antecedents and consequences of shared beliefs about failure in organizational work groups. J Org Behav 22:161-177

Carroll GR (1983) A stochastic model of organizational mortality: review and reanalysis. Soc Sci Res 12:303-329

Carter R, van Auken H (2006) Small firm bankruptcy. J Small Bus Manag 44(4):493-512

Castrogiovanni GJ (1996) Pre-startup planning and the survival of new small businesses: theoretical linkages. J Manag 22(6):801-822

Chaganti R, DeCarolis D, Deeds D (1996) Predictors of capital structure in small ventures. Entrep Theory Pract 20(2):7-18

Cochran AB (1981) Small business mortality rates: a review of the literature. J Small Bus Manag 19:50-59

Collett N, Pandit NR, Saarikko J (2014) Success and failure in turnaround attempts. An analysis of SMEs within the Finnish restructuring of enterprises act. Entrep Reg Dev 26(1-2):123-141

Creditreform (2012) Corporate insolvencies in Europe 2012/2013. A survey by the Creditreform Economic Research Unit. http://www.creditreform.com/fileadmin/user_upload/CR-International/ local_documents/Analysen/Corporate_Insolvencies_12_13.pdf. Accessed 18 Mar 2017

Crutzen N, Van Caillie D (2008) The business failure process: an integrative model of the literature. Rev Bus Econ 53(3):288-317

D'Aveni RA (1989) The aftermath of organizational decline: a longitudinal study of the strategic and managerial characteristics of declining firms. Acad Manag J 32(3):577-605

Dean TJ, Brown RL, Bamford CE (1998) Differences in large and small firm responses to environmental context: strategic implications from a comparative analysis of business formations. Strateg Manag J 19:709-728

Dunne T, Roberts MJ, Samuelson L (1989) The growth and failure of US manufacturing plants. Q J Econ 104(4):671-698

Esteve-Perez S, Manez-Castillejo JA (2008) The resource-based theory of the firm and firm survival. Small Bus Econ 30:231-249

European Commission (2003) Commission recommendation of 6 May 2003 concerning the definition of micro, small and medium-sized enterprises. http://data.europa.eu/eli/reco/2003/361/oj. Accessed 18 Mar 2017 
European Commission (2015) Annual report on European SMEs 2015/2016. https://ec.europa.eu/jrc/ sites/jrcsh/files/annual_report_-_eu_smes_2015-16.pdf. Accessed 3 May 2017

Fichman M, Levinthal DA (1991) Honeymoons and the liability of adolescence: a new perspective on duration dependence in social and organizational relationships. Acad Manag Rev 16(2):442-468

Franks JR, Nyborg KG, Torous WN (1996) A comparison of US, UK, and German insolvency codes. Financ Manag 25(3):86-101

Freeman J, Carroll GR, Hannan MT (1983) The liability of newness: age dependence in organizational death rates. Am Sociol Rev 48:692-710

Gaskill LAR, Manning RA, van Auken HE (1993) A factor analytic study of the perceived causes of small business failure. J Small Bus Manag 31(4):18-31

Hall G (1992) Reasons for insolvency amongst small firms: a review and fresh evidence. Small Bus Econ 4:237-250

Hannan MT (1998) Rethinking age dependence in organizational mortality: logical formulations. Am J Sociol 104(1):126-164

Hannan MT, Freeman JH (1977) The population ecology of organizations. Am J Sociol 82:929-964

Hannan MT, Freeman JH (1984) Structural inertia and organizational change. Am Sociol Rev 49:149-164

Hannan MT, Freeman JH (1989) Organizational ecology. Harvard University Press, Cambridge

Haveman HA (1992) Between a rock and a hard place: organizational change and performance under conditions of fundamental environmental transformation. Adm Sci Q 37:48-75

Headd B (2003) Redefining business success: distinguishing between closure and failure. Small Bus Econ 21(1):51-61

Henderson AD (1999) Firm strategy and age dependence: a contingent view of the liabilities of newness, adolescence, and obsolescence. Adm Sci Q 44:281-314

Hilbe JM (2009) Logistic regression models. Chapman Hall/CRC, Boca Raton

Hyder S, Lussier RN (2016) Why businesses succeed or fail: a study on small businesses in Pakistan. J Entrep Emerg Econ 8(1):82-100

Jennings PL, Beaver G (1995) The managerial dimension of small business failure. Strateg Change 4(4):185-200

Jovanovic B (1982) Selection and the evolution of industry. Econometrica 50(3):649-670

Kücher A, Feldbauer-Durstmüller B, Duller C (2015) The intellectual foundations of business failure: a co-citation analysis. J Int Bus Econ 15(2):13-38

Levinthal D (1991) Random walks and organizational mortality. Adm Sci Q 36:397-420

Lukason O, Hoffman RC (2015) Firm failure causes: a population level study. Probl Perspect Manag $13: 45-55$

Lussier RN (1995) A nonfinancial business success versus failure prediction model for young firms. J Small Bus Manag 33(1):8-20

Lussier RN, Sonfield MC (2015) "Micro" versus “small” family businesses: a multinational analysis. J Small Bus Enterp Dev 22(3):380-396

Madsen PM, Desai V (2010) Failing to learn? The effects of failure and success on organizational learning in the global orbital launch vehicle industry. Acad Manag J 53(3):451-476

Mayr S, Mitter C, Aichmayr A (2017) Corporate crisis and sustainable reorganization: evidence from bankrupt Austrian SMEs. J Small Bus Manag 55(1):108-127

Mellahi K, Wilkinson A (2004) Organizational failure: a critique of recent research and a proposed integrative framework. Int J Manag Rev 5(1):21-41

Mellahi K, Wilkinson A (2010) Managing and coping with organizational failure: introduction to the special issue. Group Org Manag 355:531-541

Navaretti GB, Castellani D, Pieri F (2014) Age and firm growth: evidence from three European countries. Small Bus Econ 43:823-837

Ooghe H, De Prijcker S (2008) Failure processes and causes of company bankruptcy: a typology. Manag Decis 46(2):223-242

Perry CS (2001) The relationship between written business plans and the failure of small businesses in the US. J Small Bus Manag 39(3):201-208

Ropega J (2011) The reasons and symptoms of failure in SME. Int Adv Econ Res 17(4):476-483

Saridakis G, Mole K, Storey DJ (2008) New small firm survival in England. Empirica 35:25-39

Stinchcombe AL (1965) Social structure and organizations. In: March JG (ed) The handbook of organizations. Rand McNally Co, Chicago, pp 142-193

Strotmann H (2007) Entrepreneurial survival. Small Bus Econ 28(1):87-104 
Theng LG, Boon JLW (1996) An exploratory study of factors affecting the failure of local small and medium enterprises. Asia Pac J Manag 13(2):47-61

Thornhill S, Amit R (2003) Learning about failure: bankruptcy, firm age and the resource-based view. Org Stud 14(5):497-509

Tushman ML, Anderson P (1986) Technological discontinuities and organizational environments. Adm Sci Q 31:439-465

Watson J, Everett JE (1996) Do small business have high failure rates? J Small Bus Manag 34(4):45-62

Watson J, Everett JE (1999) Small business failure rates: choice of definition and industry effects. Int Small Bus J 17(2):31-47

Weitzel W, Jonsson E (1989) Decline in organizations: a literature integration and extension. Adm Sci Q 34(1):91-109

Zacharakis AL, Meyer GD, DeCastro J (1999) Differing perceptions of new venture failure: a matched exploratory study of venture capitalists and entrepreneurs. J Small Bus Manag 37(3):1-14 